\title{
EVALUATION OF FACTORS THAT INFLUENCE SCHOOL FAILURE IN A GROUP OF ADOLESCENTS IN IASI COUNTY
}

\author{
Adriana Albu, Mihaela Vlada ${ }^{2}$, \& Florin Dima ${ }^{2}$ \\ ${ }^{1}$ Grigore T. Popa University of Medicine and Pharmacy (Romania) \\ ${ }^{2}$ Vaslui Department of Public Health (Romania)
}

\begin{abstract}
Introduction: school activity is characterized by high physical and mental demands. Any failure to adapt these requests to the possibilities of the age group can be associated with school failure. Material and method: the study was carried out on a group of 208 students from the 9th grade from a National College in Iasi (54 students), a National College in Pascani (80 students) and from an Economic High School in Iasi (74 students). A questionnaire regarding school activity and the causes of the phenomenon of school fatigue was applied. The results were processed using Pearson's chi-squared test. Results and discussions: The students are constantly preparing only for certain subjects $(72.59 \%)$. The young people from the National College in Iasi stand out, as we find numerous answers of "I do not continuously prepare for any subject", so the calculated differences are statistically significant $(\mathrm{p}<0.01, f=4$, $\left.\chi^{2}=14.254\right)$. In most cases $(65.86 \%)$ adolescents admit that they have been trained how to study only in certain subjects. In the students from the National College in Iasi there are few explanatory answers in all the disciplines, so the calculated differences are statistically significant ( $\left.p<0.001, f=4, \chi^{2}=19,465\right)$. Young people study for pleasure only in certain disciplines $(86.53 \%)$. At the National College in Iasi there are no students who study for pleasure in all disciplines, so the differences obtained are statistically significant $\left(\mathrm{p}<0.05, f=4, \chi^{2}=11.072\right)$. Fatigue is often present in $58.65 \%$ of students, with significant differences between high schools $\left(\mathrm{p}<0.05, f=4, \chi^{2}=11.807\right)$. The students attribute the occurrence of this phenomenon to the numerous subjects they have to study $(55.76 \%$ - statistically insignificant differences), the large volume of homework $(51.92 \%$ - significant differences) and insufficient sleep (48.55\% - statistically insignificant differences). Conclusions: there are many factors that generate school failure that must be known and carefully assessed in order to reduce the frequency of this phenomenon.
\end{abstract}

Keywords: School failure, fatigue, demanding activity.

\section{Introduction}

In Romania, in the past few years, we have witnessed a drastic decrease in the number of young people graduating high school and passing the baccalaureate exam. It is a school failure situation that is becoming worrying. The indicators used to assess this phenomenon are represented by the early abandonment of studies, the gap between the student's potential and their results, abandoning school without a qualification and failing the final exams. The appearance of the phenomenon of school failure is favored by a number of factors related to the student, school or family (Cosmovici \& Iacob, 2008).

Of the factors that regard the student, health must be given special attention. We must be aware of certain organic diseases, physical or sensory deficiencies and some individual psychological factors. In adolescents, the aspects related to nutrition and physical exercise become essential due to the current beauty ideal represented by the thin young woman and the muscular young man (Nagata, Ferguson \& Ross, 2016; Salam, Das, Lassi \& Bhutta, 2016). Particular attention should be paid to overweight students who will be the target of their colleagues' jokes. This will make them focus too much on their own body and isolate themselves (Abălașei \& Trofin, 2016).

The school environment must ensure lasting social development, to practically guarantee the progress of society. In this sense, it is necessary to find the answers to the following questions: what are the characteristics that need to be structured to ensure the adaptation of young people to the new requirements; what kind of education do students need, to contribute to the progress of society in the future; which are the skills, information, and attitudes that are needed to ensure a better future (Xie, 2018). 
The school has many roles; it also decisively contributes to promoting healthy eating, physical exercise, ensuring the physical and mental health of students, developing social relationships and avoiding the tendency of isolation (Sabinsky, Hostgaard Bonde, Sternqvist, Jessen -Klixbüll, Maindal \& Tetens, 2018).

Particular attention should be paid to the school syllabus and the teaching method of the teachers. The teaching method must be oriented towards the student, in the direction of obtaining the expected results.

Teachers must focus on the issues related to the best teaching methods, methodologies and techniques. They must ask themselves the question (and find the answer) "How to teach?" and not the one related to the curriculum, "What to teach?" (Sousa, 2019).

The family plays an important role in the life and evolution of the young man. At present, it is also necessary to assess the relationship that exists between family and school. In the traditional model, the teachers carry out their activity in isolation, in their own style. Lately, we are witnessing some changes related to the structure of a close relationship with the family, the interaction between school and family. In many schools parents are invited to be part of the school program, to have the feeling of belonging (Palmieri \& Palma, 2017).

\section{Objectives of the study}

Evaluation of students' learning method; assessment of the involvement of teachers in the instruction of the students on the learning method and the interest of the students for school activity: knowing the presence of the phenomenon of school fatigue and of the factors that generate it.

\section{Material and method}

The studied group consists of 208 students from the 9th grade from a National College in Iasi (54 teenagers), a National College in Pascani (80 young people) and from an Economic High School (74 students) in Iasi. Pascani is a small town located $60 \mathrm{~km}$ from Iasi. The city of Iasi has a large number of inhabitants, while also being the county capital. The National College in Iasi is an elite high school for Iasi County and even for the entire country.

The students completed a questionnaire with questions regarding the school activity and the causes of the phenomenon of school fatigue. School activity was assessed with the help of 3 questions. "Do you study continuously, without losing a lesson?" - yes, in all subjects; only in certain subjects; I am not constantly preparing myself for any subject. "Did the teachers explain how to learn and solve the problems in the studied discipline?" - yes, in all subjects; only in certain subjects; no, in none of the studied subjects. "Do you study for pleasure?" - yes, in all subjects; only in certain subjects; no, in none of the studied subjects.

Fatigue was assessed with the help of two questions. "Do you feel tired? - often; rarely; never." What causes your fatigue?" (choose the answers that you think are most important) - subjects are too difficult; the classes are too numerous (every day or during the week); the large volume of homework; I don't get enough sleep;

Also concerning the problem of fatigue, we will address issues related to the number of hours of sleep per night (under 8 hours; 8-9 hours; over 9 hours).

The results were processed using the Pearson CHI square test.

\section{Results}

We will address two basic aspects related to school activity and the presence of fatigue.

Sustained school activity strains the student from a neuropsychological and physical point of view. Obtaining meritorious school results can be achieved only under the conditions of a systematic study in all subjects. Unfortunately, such a situation is present in only $16.82 \%$ of young people. In most cases, students pay attention only in certain subjects $(72.59 \%)$ (Table 1$)$.

Table 1. Learning method of students.

\begin{tabular}{|c|c|c|c|c|}
\hline School & Pascani College & Iasi College & Iasi High School & Total \\
\hline yes, in all subjects & 14 & 7 & 14 & $35-16.82 \%$ \\
\hline only in certain subjects & 61 & 34 & 56 & $151-72.59 \%$ \\
\hline $\begin{array}{c}\text { I am not constantly preparing } \\
\text { for any subject }\end{array}$ & 5 & 13 & 4 & $22-10.57 \%$ \\
\hline
\end{tabular}


Our attention is drawn to the $10.57 \%$ of students who are not constantly preparing for any subject. Such answers are more frequent at the Iasi College, so the calculated differences are statistically significant ( $\left.\mathrm{p}<0.01 f=4, \chi^{2}=14.254\right)$. It is a surprising result given that the college in Iasi is an elite school.

Students receive explanations on learning methods only in certain studied disciplines $(65.86 \%)$, so only from certain teachers (Table 2).

Table 2. Frequency of explanations received by students on learning methods.

\begin{tabular}{|c|c|c|c|c|}
\hline School & Pascani College & Iasi College & Iasi High School & Total \\
\hline yes, in all subjects & 29 & 4 & 27 & $60-28.84 \%$ \\
\hline only in certain subjects & 50 & 45 & 42 & $137-65.86 \%$ \\
\hline $\begin{array}{c}\text { I am not constantly preparing } \\
\text { for any subject }\end{array}$ & 1 & 5 & 5 & $11-5.28 \%$ \\
\hline
\end{tabular}

We can observe that $28.84 \%$ of teenagers chose the "yes, in all subjects" answer. Such answers are less frequent in those from the college in Iasi, so the calculated differences are statistically significant $\left(\mathrm{p}<0.001 f=4, \chi^{2}=19,465\right)$.

Most of the students study for pleasure only on certain subjects $(86.53 \%)$, with only $3.84 \%$ studying seriously in all subjects (Table 3 ).

Table 3. The number of students who study for pleasure.

\begin{tabular}{|c|c|c|c|c|}
\hline School & Pascani College & Iasi College & Iasi High School & Total \\
\hline yes, in all subjects & 2 & 0 & 6 & $8-3.84$ \\
\hline only in certain subjects & 75 & 45 & 60 & $180-86.53 \%$ \\
\hline $\begin{array}{c}\text { I am not constantly preparing } \\
\text { for any subject }\end{array}$ & 3 & 9 & 8 & $20-9.61 \%$ \\
\hline
\end{tabular}

There are young people who do not study for pleasure in any discipline, a situation which is alarming. Such a response occurs more frequently in students from the Pascani college, the differences calculated being significant $\left(\mathrm{p}<0.05 f=4, \chi^{2}=11.072\right.$ ).

Intense school demands lead to certain responses from the body and fatigue. Fatigue is often felt by $58.65 \%$ young people (Table 4 ).

Table 4. Frequency of fatigue.

\begin{tabular}{|c|c|c|c|}
\hline School & Often & Rarely & Never \\
\hline Pascani College & 43 & 36 & 1 \\
\hline Iasi College & 42 & 11 & 2 \\
\hline Iasi High School & 37 & 35 & 4 \\
\hline Total & 122 & 82 & 1.92 \\
\hline$\%$ & $58.65 \%$ & 39.42 & \\
\hline
\end{tabular}

For students from the college in Iasi the dominant answers are "often", so the calculated differences are statistically significant $\left(\mathrm{p}<0.05 f=4, \chi^{2}=11,807\right)$.

Students attribute fatigue to the large number of hours in the school program $(55.76 \%$ - with insignificant differences among schools $\left.\mathrm{p}>0.05, f=2, \chi^{2}=1.330\right)$, to the high volume of homework $\left(51.92 \%\right.$ - significant differences $\left.\mathrm{p}<0.05, f=2, \chi^{2}=6,900\right)$ and the reduced number of hours of sleep per night (48.55\% - insignificant differences $\left.\mathrm{p}>0.05, f=2, \chi^{2}=3.353\right)$ (Table 5).

Table 5. Causes attributed by students to the occurrence of fatigue.

\begin{tabular}{|c|c|c|c|c|}
\hline School & Pascani College & Iasi College & Iasi High School & Total \\
\hline subjects are too difficult & 23 & 15 & 24 & $62-29.80 \%$ \\
\hline the classes are too numerous & 48 & 27 & 41 & $116-55.76 \%$ \\
\hline the large volume of homework & 34 & 27 & 47 & $108-51.92 \%$ \\
\hline I don't get enough sleep & 36 & 32 & 33 & $101-48.55 \%$ \\
\hline
\end{tabular}

Insufficient sleep is one of the factors that cause fatigue. In students, the normal number of hours of sleep per night is $8-9$ hours, an answer which is present only in $29.80 \%$ of situations. In most cases $(66.82 \%)$ students sleep fewer than 8 hours per night, which is not physiological and explains the onset of fatigue (Table 6). 
Table 6. Hours of nighttime sleep.

\begin{tabular}{|c|c|c|c|c|}
\hline School & Pascani College & Iasi College & Iasi High School & Total \\
\hline Under 8 hours & 44 & 37 & 58 & $139-66.82 \%$ \\
\hline 8-9 hours & 32 & 17 & 13 & $62-29.80$ \\
\hline Over 9 hours & 4 & 0 & 3 & $7-3.36 \%$ \\
\hline
\end{tabular}

Most students from the Iasi College sleep fewer than 8 hours per night, the differences calculated being statistically significant $\left(\mathrm{p}<0.01 \mathrm{f}=4, \chi^{2}=12.334\right)$.

\section{Discussions}

Concerning school activity, the workstyle of each student is very important. In the studied group there are many students who systematically study only certain subjects and who enjoy studying certain subjects. There are numerous differences between students in a class that have to do with the characteristics of physical development, intelligence, interest, perception, abilities, learning style and personality. Starting from these aspects it would be necessary to adapt the lesson plan to the students' learning style and speed, and not focus on collective education (Kubat, 2018). If these aspects are not taken into account, we may reach a situation similar to that of the students in the studied group where in $9.61 \%$ of cases they do not study for pleasure any subject in the school syllabus.

Learning style is influenced by a number of psychological, physiological, emotional, social and environmental factors, so the talent of the teachers is essential in solving these problems and in finding the best methods of teaching and stimulating the students (Ozdemir, Alaybeyoglu, Mulayim \& Uysal, 2018).

In solving these problems, an essential role rests with the teachers who can instruct the students on learning methods in each discipline of study. Unfortunately, in the studied group most of the answers $(65.86 \%)$ are for explanations "only in certain subjects". This is where the experience of the teachers comes in, as well as their working environment represented by job satisfaction, the recognition of efforts, their well-being (De Stasio, Boldrini, Ragni \& Bacile, 2019).

School activity is inherently associated with the occurrence of fatigue of greater or lesser intensity. In the studied group, fatigue is most often present in $58.65 \%$ of students. We notice the students from the Iasi College, an elite high school, where competition is a basic element and where fatigue is more prevalent. In the case of students from computer science high schools in the area of Moldova, fatigue often appears only in $42.39 \%$ of situations, the dominant answers being "rarely" $(50.54 \%)$ (Albu, Dima, Dorofte \& Abdulan, 2017). At technical colleges, fatigue occurs mostly "rarely" (53.76\%), "often" representing only $34.17 \%$ of the total responses (Albu, Dima \& Badaluta, 2017).

We must pay attention to insufficient sleep, as it can lead to chronic fatigue. In adolescents the recommended number of hours of sleep per night is $8-10$, which is recognized by only one third of the questioned students. In a study also carried out on teenagers from high schools in Iasi, the situation is even worse because only $16.87 \%$ answers of " $8-9$ hours" and 7.17\% answers of "more than 9 hours" are present. Practically, only $25 \%$ of students have an adequate number of hours of sleep per night (Albu A., Hodorca R.M., Onose I., Negrea M. \& Cracana I., 2016). In a study carried out on adolescents in Ecuador, $72.1 \%$ of young people do not comply with the rules regarding sleep duration. This is a worrying result because in Brazil's adolescents there are only $39 \%$ cases of insufficient sleep, and in Argentina 49\%. In these young people the average sleep duration is 7.96 hours for younger students and decreases for older students down to 7.08 hours (Villa-González, Huertas-Delgado, Chillón, Ramirez-Vélez \& Barraco-Ruiz, 2019).

In Rhode Island adolescents, the average sleep duration is 8.79 hours, so it is a better result compared to adolescents in Ecuador (Miller, Janssen \& Jackson, 2017). In adolescents from Japan in 2017, the number of cases of sleep under 6 hours was 43.9\% much higher compared to the one obtained in 2003 of $36.6 \%$ (Yamamoto, Ota, Minematsu, Motokawa, Yokoyama, Yano, Watanabe and Yoshizaki, 2018).

Special attention should be paid to students who have insufficient hours of sleep because they can easily reach the point where they use substances that remove the feeling of chronic fatigue and even some legal drugs such as coffee, alcohol and tobacco (Baciu 2019; Miller, Janssen and Jackson, 2017). 


\section{Conclusions}

It is necessary to pay special attention to the way students adapt to school requirements. In the studied group there are many young people who do not constantly prepare for all subjects and who study for pleasure only certain subjects. A particular problem is the one related to teaching style because the students received explanations on learning methods only in certain subjects.

Fatigue is present in most students, but students from elite high schools are most exposed to this reaction. A particular problem is that of fatigue, which is due to the large number of hours in the school program, the large volume of homework and insufficient sleep. Insufficient sleep is a problem for most students because it favors the onset of chronic fatigue followed by school failure.

Such studies are essential for maintaining the health of the students and ensuring the expected school results.

\section{References}

Abălașei, B., \& Trofin, F. (2016). Considerations on the correlation between real body and body image. Timişoara Physical Education and Rehabilitation Journal, 9(16),7-12.

Albu, A., Dima, F., \& Badaluta, A. (2017). School fatigue and the factors that influence it, LUMEN Proceedings, 4, 9-18.

Albu, A., Dima, F., Dorofte, S., \& Abdulan, I. (2017). School fatigue and free time activities in a group of adolescents from two information technology high schools. The Educational Review, USA, 1(3), 47-53.

Albu, A., Hodorca, R. M., Onose, I., Negrea, M., \& Cracana, I. (2016). The evaluation of the scholar fatigue and some causative factors in a group of teenagers from Iasi. Global journal of Sociology: Current Issues, 6(2), 44-49.

Baciu, A. (2019). Aspects regarding the influence of family and the social pees group on drug use in a lot of pupils and students from Bucharest. Anthropological Researches and Studies, 9, 153-160.

Cosmovici, A., \& Iacob, L. (2008). Psichologie scolara, Iasi, Romania: Ed. Polirom.

De Stasio, S., Boldrini, F., Ragni, B., \& Bacile, C. (2019). Protective factors contributing to teacher-working environment fit in Italian teachers' sample. Anthropological Researches and Studies, 9, 5-14.

Kubat, U. (2018). Identifying the individual differences among students during learning and teaching process by science teachers. International Journal of Research in Education and Science, 4(1), 30-38.

Miller, M. B., Janssen, T., \& Jackson, K. (2017). The prospective association between sleep and initiation of substance use in young adolescents. Journal of Adolescent Health, 60, 154-160.

Nagata, J., Ferguson, J., \& Ross, D. (2016). Research priorities for eight areas of adolescent health in low- and middle-income countries. Journal of Adolescent Health, 59, 50-60.

Ozdemir, A., Alaybeyoglu, A., Mulayim, N., \& Uysal, M. (2018). An intelligent system for determining learning style. International Journal of Research in Education and Science, 4(1), 208-214.

Palmieri, C., \& Palma, M. (2017). The relationship between school and community as an opportunity to re-think teaching. New Trend and Issues Proceeding on Humanities and Social Sciences, 4(1), 496-503.

Sabinsky, M., Hostgaard Bonde, A., Sternqvist, N. W., Jessen-Klixbüll, E., Maindal, H. T., \& Tetens, I. (2018). The "we act"-study: design of a multicomponent intervention to promote healthy diet, physical activity, and well-being in school children. Journal of Food and Nutrition Research, 6(9), 602-613.

Salam, R., Das, J., Lassi, Z., \& Bhutta, Z. (2016). Adolescent health and well-being: background and methodology for review of potential intervention. Journal of Adolescent Health, 59, S4-S10.

Sousa, J. M. (2019). Aiming at an emancipatory curriculum. Education Journal, 8(3), 89-96.

Villa-González, E., Huertas-Delgado, F., Chillón, P., Ramirez-Vélez, R., \& Barraco-Ruiz, Y. (2019). Association between active commuting to school, sleep duration, and breakfast consumption in Ecuadorian young people. BMC Public Health, 19:85.

Xie, C. (2018). The new crucial goal of world education: the quality of sustainable. Education Journal, $7(2), 37-42$

Yamamoto, K., Ota, M., Minematsu, A., Motokawa, K., Yokoyama, Y., Yano, T., Watanabe, Y., \& Yoshizaki, T. (2018). Association between adherence to the Japanese food guide spinning top and sleep quality in college students. Nutrients, 10, 1996. 